\title{
Justicia social, legitimidad y legalidad: la sociedad civil ante el defensor del pueblo en Argentina
}

\author{
GABRIELA DALLAA CORTE*Y SILVLA GÓMEZ I MESTRES**
}

Resumen: Si algo ha cavacterizado la discusion sobre ia indole de la justicia a lo lango del sigho $\mathrm{xx}$ es la distinaion entre justicia legal y justicia sacial. En este debate se inscribe el arcionar del ombudsman, institución sin fuerza vinculante ni pode, peo que goza de autoridad para proponer modificaciones juridicas y adwinistrativas tendentes a arwonizar tas dennandas sociales con el sistema juridico. La presencal del ombudsman se ho extendido poderosanente en lex última derada en América Latina; en su desempeño vuetra las disonancias entre los sistemas palíticas, on teoria representativos, y las necesidades de los representedos. El presente aludio abonda los conflictos que ha habido entre ol defensor del pueblo nacional de la República Argentina y las ampresas monopóticas del pais que controlan los servicios priblicos exenciales. Estudiamos la indole de la inctitución y su capacidad real para generar cambios normatives con base sacial.

\begin{abstract}
One of the most important characteristics in the discussion on the notare of justice throughout the $. x \times$ century has been the distinction betaon legal and social justice. This debate indudes the work of the ombudsman, an instifution with no binding force on pour yet with the authority to propose legal and administrative wodifications aimed at reconciling social demands with the legal systen. The ombuds. man has become a familiar figure over the past decade in Latin America; houner, his performance has shoun the lach of coincidence between political gystems, that are supposedily representative, and the neads of those being requeserited. This study addresses the conficts hatroen the defender of the people in Angentina and the monopolistic farms in the country itat control basic prettic services. It studies the natuse of the institution and its capacity to give berth to changes in norms athich can have a social basis.
\end{abstract}

Palabras clave ombudsman, sociedad, queja, legitimidad, justicia.

Key words: ombudsman, society, complaint, legitimacy, justice.

\section{EN TORNO AL OMBUDSMAN}

$D$ ESDE SU SURGIMIENTO PLENO A PRINCIPIOS del siglo XIX, y a pesar de la variedad de atribuciones y competencias que ha ido adquiriendo la institución del ombudsman en su expansión mundial, su común denominador es la tutela de los ciudadanos ante posibles abusos de la administración pública. Su origen

* Gabriela dalla Corte: historiadora, doctora en Historia, especialidad en Historia de América, por la Universidad de Barcelona. Becaria Fomec por la Universidad Nacional de Rosario, Argentina. Doctoranda en el programa "La recerca de camp en Antropologia Social”, Departament d'Antropologia Cultural, História d'Amèrica i Africa, de la Universidad de Barcelona. Ditighí correspondencia a: Calle Vistalegre 26, Bajos 1o, CP 0SCO1, tel.: 9332943 74, Barcelona, Espana; e-nail: zulmafecitynet.net.ar:

**Silvia Gómex i Mestres: antropóloga. Becaria de Recerca i Docència de la Universidad de Barceluna. Doctoranda en el programa "La recerca de camp en Antrologia Social", Departamen! d'Antropologia Cultural, História d'Amèrica i Africa e la Universidad de Barcelona. Dirigir correspondencia a: Calle Bailén 154, $1^{\circ} 2^{\circ}$, Barcelona, CP 08037, España; e-mail: sgontezotrivium.gh,ub.es.

[69]

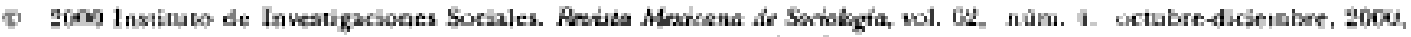
México. D. F. pp. 60900. ISSN: 0138-2503/00/06904-04/ USD 1.50 is 5.00 . 
institucional se remonta a la Suecia del año 1809, en un particular momento histórico marcado por las luchas entre dos de los poderes configurativos del Estado moderno: el Parlamento y la monarquía, aunque su aparición en escena data del año 1713, cuando un decreto de Carlos XII creó el cargo de representante del rey (Konungens Hôgsts o hôste Ombudsmannen) para supervisar a los oficiales, vigilar el respeto a la ley estatuida así como el cumplimiento de las obligaciones de los funcionarios de gobiernu. En $1719 \mathrm{el}$ höste ombrudsmannen cambió su nombre por el de justitieKansler (canciller de Justicia) y este último asumió la tarea de actuar como procurador en caso de violación a normas constitucionales y de rendir cuentas al poder legislativo. Muy pronto, como afimó́ uno de los más reconocidos ombudsman en asuntos civiles de Suecia, Alfred Bexelius, se percibió que la figura carecía de suficiente independencia en relación con el gobierno. ${ }^{1}$ En respuesta, fue ideada la figura del Justitie-Ombudsman, cuya finalidad era canalizar en el Parlamento las quejas de los súbditos. ${ }^{2}$

En 1772, la Constitución de Gustavo Adolfo restableció la autoridad de la monarquía, aunque el ombudsman se convirtió en procurador del Parlamento para impedir a la Corona su influencia sobre el poder judicial. ${ }^{3}$ Esta ofensiva parlamentaria, sin embargo, encontró resistencias en 1789 cuando Gustavo III decidió concederse a si mismo plenos poderes, por lo cual el canciller de Justicia volvió nuevamente a su égida. Su asesinato en 1792, y la deposición de su sucesor, Gustavo Adolfo rv, llevada a cabo por una rápida y certera revolución, volvió insostenible el conflicto entre ambos poderes. La guerra de los años 1808 y 1809 condujo, además, a un empobrecimientu profundo de la población sueca. En 1809, al ser restaurados los poderes del Parlamento con la paz de Tilsitty la Regencia de Carlos XIII, se recuperó e institucionalizó la figura de contralor mediante la creación del ombndsmany su legítimación en la Constitución adoptada ese año. Dicha Constitución (Regeriusform), influida por las teorías de Montesquieu, fue votada por la Dieta vigente en Suecia y garantizó la distribución del poder entre la Corona y su Consejo, el Parlamento y las Cortes, bajo un sistema de absolutismo regio moderado con poder del Parlamento. La figura del ombuclsman aseguró su independencia de la Corona y del gobierno al establecer su pertenencia al órgano legislativo. El artículo 96 de la Constitución sueca lo definió en calidad de "delegado del Parlamento" con la tarea de vigilar el cumplimiento de leyes y regla-

\footnotetext{
${ }^{1}$ Alfred Bexelius, "Sweden's guardians of the law: 'The ombudsman of cisil affairs", en Donald Rowat (comp.), The Ombudsnan, Citizen's Defende, Loudres, 2n. ed., George Allen \& Linwin Lud. 1968.

"Salvatore Maccarone, "Le esperienze curopee di ombudsman baticario", en Franco Riolo, Le innca o lestitwoto: strumenti arbitmali e ombudsman bancavio nuovi metori per la risoluzione di controwess; 'Roma, Bancaria, 1994, pp. 33.34; A. di Giovine, 'L'ombudsman in Scandinavia", en Costantino Mortati (comp.), L'ounbudsaisn (Il difensore civico). Tutiu, Unione 'Tipografiea Edierice Torinese, vol. 3, 1974, pp. 15.58 .

${ }^{3}$ Giovanni Napione, L' Ombudsman, Rorna, Tipologia delle Terme, 1969, p. 5; V. Fairen Gailk·n, EI defensor ded pueblo-ombadstron, tomo I. Parte Gerieral, Madid, Centro de Estudios Constitucionales, 1989, p. \$3; Daxid Robertson, A Dietionary of Human Rights, Londres, Europa Publications Limited,

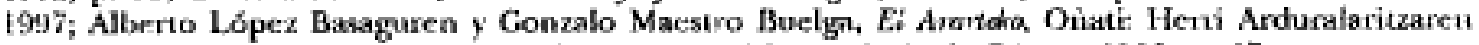
Euskal Erakundea, Próloggo del Ararteko Juan San Martín Ortiz de Zarate, 1999, p. 57.
} 
mentos, de controlar el poder atribuido al rey en el campo ejecutivo, y de disminuir la influencia del gobiemo en el aparato administrativo y jurisdiccional. ${ }^{4}$

El vocablo sueco ombudsman (derivación de la raíz umbud, que quiere decir poder y autoridad) significa literalmente "hombre que hace de trámite, que da trámite o que tramita", y se refiere a las personas que actúan como representantes de otras. A pesar de que se trata de una institución surgida en Suecia, el ombudsman ha venido incorporándose en las estructuras institucionales nacionales, regionales, provinciales y locales en todos los continentes. Esta expansión, sin embargo, no se produjo de manera inmediata a la legitimación institucional del ombrudsman, sino que debió esperar más de una centuria para imponerse en el resto de los países nórdicos. Finlandia fue el primer Estado que adoptó la figura en su Constitución de 1919, luego de independizarse de Rusia; Dinamarca comenzó a discutir la necesidad de contar con dicha institución después de la segunda Guerra Mundial, aportando la novedad de su inclusión en el sistema jurídico de corte napoleónico. La República Federal de Alemania, por su parte, aceptó implantar un cargo análogo en 1957 para transformar la insuucción militar y evitar el resurgimiento de los hábitos racistas, contrarios a los derechos humanos, propios de las extinguidas fuerzas armadas. ${ }^{5}$

Como vemos, la legitimación del mnbrudsman en el mundo coincidió con el fin de la segunda Guerra Mundial, el proceso de descolonización. la emergencia de los nuevos movimientos sociales en el escenario político y cultural de la década de los sesenta y con el desarrollo de teorías fundadas en la valoración del Estado de derecho. Hacia principios de esa década, las competencias del ombudsman estaban casi plenamente establecidas y el proceso de difusión internacional se puso en marcha, en un principio en el resto de Enropa. En España, país cuya normativa sobre la institución ha sido imitada en América Latina, el ombudsman fue presentado a la sociedad civil como el "luchador en defensa de los ciudadanos", como una institución caracterizada por su sencillez y con la finalidad de vigilar los excesos de los poderes públicos. Incorporado como comisionado pariamentario en el capítulo relativo a las garantías de las libertades y derechos fundamentales de la Constitución de 1978, comenzó a regir seis an̂os después con el argumento de que era "uno de los índices y argumentos más elocuentes cle la valiclez del sistema democrático". El nombre adoptado por el Parlamento fue el de defensor del pueblo y, notablemente, esta "fórmula" (que muchos calificaron de demagógica) se le ocurrió al político Manuel Fraga, antiguo ministro del dictador Francisco Francoy, en ese entonces, jefe máximo de la organización de derecha denominada "Alianza Popular", la cual en la actualidad conserva el poder en la persona del presidente de la nación, José María Aznar, líder del Partido Popular. El primer defensor

\footnotetext{
i Aivaro Gil-Robles y Gil Delgado, -Filosofía dei defensot del pueblo", en Paloma Biglino Campos (comp.). El procurador del cowún: defensor del puebio y comunidades autönomas, Jomadias de Estudio, Valladolid, tiniversidad de Valladolid, 1995, p. 26; Antonio Aradilas, Todo sobre d defensor del pueblo, Barcelona, Plaza \& Janés, 1985, p. 24.

5 La nodificacion constitucional corrió a cargo del dipotado socialista Ernst Paul quien, durante la época de flitler, debió exiliarse en Suecia, donde pudo estudisr el desenvolvimiento de la figura.
} 
del pueblo de España, Joaquín Ruiz Giménez, fue, por su parte, ministro de Cultura de Franco, y resultó elegido por el Partido Socialista Obrero Español (PSOE). ${ }^{5}$

Gradualmente, la figura aunenta, se expande, se transforma y cambia su campo de actuación, pero en todos los países su tarea es tuitiva porque supone la defensa del ciudadano (a )en diversas instancias de instauración de la figura: los medios de comunicación, el gobiemo o la Universidad. El ombudsman se proyectó tambiên hacia las antiguas colonias europeas en América Latina y África, proceso que se vio favorecido por la continua propaganda de las Naciones Unidas y por el apoyo económíco que otorgó este organismo para la realización de un seminario especializado en jamaica en el año de 1967, en el que participaron muchos representantes de América Latina, los cuales resultaron influidos por el ombudsman civil sueco, Bexelius, para impulsar el desarrollo de la figura en sus países "subdesarrollados". ${ }^{7}$ En el área sur de Europa, por otra parte, su generalización coincide con la emisión, por parte del Comité de Ministros del Consejo de Europa, de la resolución de difundir dicha figura en el nivel nacional, regional y local durante la década de los ochenta. ${ }^{8}$

Con estos antecedentes, el ombudsman empezó a ser estudiado en ámbitos acidémicos universitarios, analizado en jornadas, congresos y encuentros específicos con gran apoyo económico de fundaciones e instituciones estatales, y fue incorporado a la mayor parte de los ordenamientos políticos. La cantidad de oficinas se cuadruplicó durante la última década del siglo XX: si en 1993 alrededor de 21 países contaban con un ombudsmany otros seis lo hacían en el nivel provincial/estatal y regional, scis años después el ombudsman del sector público estaba ya incorporado en el ámbito nacional en más de 100 Estados del mundo, tanto en sistemas democráticos firmes como en democracias más recientes. En líneas generales, el titular de la oficina es elegido por el Parlamento o designado por el jefe de Estado previa consulta al ente legislativo, y su rol es proteger al pueblo de las violaciones de los derechos, abusos del poder, etrores, negligencia o decisiones injustas de la administración pública. ${ }^{9}$ Fn este sentido. da cauce e investiga quejas presentadas contra funcionarios, empleados, agencias gubernamentales o semigubernamentales, así como empresas concesionarias de scrvicios públicos; efectúa recomendaciones como resultado de sus investigaciones e in-

${ }^{6}$ Actes Conawemoratius del Xe Aniversori de la prowulgació de la thei 14-1984 del Síndic de Gienger de Catolunya (1995), Síndic de Greuges, Barcelona. Antonio Aradillas, Tudo sabre el defensor del puelia, Barcelona, Plaza \& Janés Ed., 1985, pp. 10. 15 y 37. Victor Fairen Guillen, El defonsor del puebleombudswan, tomo I, Parte Especial, Madrid, Centro de Estudios Constirucionales, 1986, p. 53. Entrevista de Andrés Osojnik a Jorge Luis Maiorano, Pógina 12, 16-10-1994.

"Donald Rowat, "Preface to second edition", en Donald Rowat (comp.), The Ombudsman, Citizen's Deferder, 2a. ed., Londres, George Allen \& Unwin Ltd. 1968, p. XX.

s Paloma Biglino Campos, "Presentación de las jomadas", en Paloma Biglino Campos (comp.), El procurador del cowún: defensor da' pueblo y cowunidedes autónomas, Jornadas de Estudio, Valladolid, Universidad de Valladolid, 1995, p. 18.

o Priwer Informe axual del defensor del pueblo de la nación axgentina al Congreso (con adelante se cita sólo /nforme anuel), tomo 1; página web del Instituto luternacional del Ombudsman, Alberta, Canactí, htip: $/ /$ www, law, ualberta.ca/centres/toi. 
forma al poder legislativo con la esperanza de poder modificar las situaciones que originan esas quejas. ${ }^{10}$

Los Estados, necesitados de un organisno legítimo para canalizar institucionalmente las demandas y los conflictos, consensuaron paralelaniente compartir el corpus jurílico homogéneo que supone el ombndsman: así pues, la difusión de la oficina ha dependido de la internacionalización de la cultura jurídica inás que del cambio coincidentenente paralelo e incontunicado entre los diversos países. Se trata de un problema central para la antopología jurídica, es decir, del grado de diseminación y propagación de instituciones concretas, de prácticas jurídicas, de modelos políticoinstitucionales y, esencialmente, de la paulatina hegemonía del modelo de democracia liberal que monopoliza los cuadros administrativos del mundo "occidental". Fuertes ha señalado dos maneras de concebir este fenómeno: pensarlo en términos de "préstamo" de instituciones o, siguiendo a Michel Alliot, considerarlo como parte: de la "enculturación jurídica", es decir, como una uansformación global del sistema juridico por contac to con otros sistemas diferentes. ${ }^{11}$ De acuerdo con nuestra exposición, queda clares que esta institución no puede ser entendida en términos locales, sino que debemos comprender la lógica de su funcionamiento en lo que jane Collier llama sociedad global, es decir, una sociedad en la que aumentan las comunicaciones y los contactos transnacionales, además de los locales, regionales y nacionales. ${ }^{12}$ En tal sentido, el proceso de intemacionalización se ha cristalizado en organizaciones no gubernamentales encargadas de canalizar la commicación entre los diversos titulares que han asumido el cargo de ombadsman en el mundo, instituciones fundadas en redes personales y profesionales como el Instituto lnternarional del Ombudsman (IOI) y la Federación Iberoamericana del Ombudsman (FlO). Dicluas entidades supranacionales unifican las prácticas, centralizan $y$ difunden centrífuga $y$ cenuípetamente las noticias; asimismo, obtienen repercusión internacional mediante un controlado flujo de información. ${ }^{13} \mathrm{El}$ desastre ecológico y humano que asoló a Centroamérica a finales de 1998, el huracan Mith, es una nutestra significativa de la densa red social que articula a los ombudsmon, en especial a los latinoamericanos y al uspanol. Cuando comenzaron las presiones de les respectivos poderes ejecutivos contra los ominudsman latinoamericanos para frenar la posibilidad de cambios sociales, aquéllos comunicaron a su par peninsular las amenazas y el interés de sus gobicrnos por

\footnotetext{
to Crabriela dalla Corte, -Mäs allit del espacio jurisliccional: ombulswan, sindic de Greuges y defensores del pueblo", en Igrasi Terradas i Saborit (coord.). Antsofologin jurition, Santiago de Compostela, 1999, pp. $778 \%$

11 N. Fueites, Noz antropologia del Derecho", en Ángel Aguitrix (comp.). Diecionario temético de Anlropologia, Barcelona, PPU, 1988, pp. 238-242.

${ }^{12}$ Jane Collier; Problemas teórico-taetodológicos en la antropología jurfidica”, en Victoria Chenaur y Ma. Teresa Sicria (coord-), Puedor indigenas anle d Denecto, México, Centro de Investigaciones y Estudios Superiores en Antropologia Social (CIFSAs)/Centro de Estudios sobac México y Cantroamérica (CEMCA), 1995.

Is David Robertson, A Dictionary of Huwan Rights, Londres, Europa Publications Linited, British t.ibary Cataloguing. 1997, p. 149; tambiéu Mario Cissaliuuovo, "Presentación", en Maria Rita Ferragina. II defensose civico: ombudsman, Rubbetino, Soweria Maunelli, 1991.
} 
continuar desamparando a los ciudadanos más afectados. El defensor del pueblo español divulgó la noticia el mismo día en la mayor parte de los medios de comunicación de masas, para condicionar a la opinión pública y así satisfacer las demandas de sus pares americanos.

En América Latina, el ınyor impulso para la difusión del ombulsman provino de la cuidadosa y estratégica elección de la ciudad de Buenos Aires como sede del vi Congreso del Ior en octubie de 1996, como habia ocurrido con cada uno de los lugares seleccionados pára los congresos anteriores organizados a partir de 1978, es decir, las ciadades de Edmonton (Alberta, Canadá), Jerusalén (Israel), Estocolmo (Suecia), Canberra (Austualia) y Viena (Austria). ${ }^{14}$ Mientras tanto, los máximos represtentantes de esta institución y sus teóricos demostraron desde el principio cierto escepticismo en relación con esta difusión. Donald Rowat senaló: "[...] hay razones que nos permiten concluir que el plan del ombudsmast no funcionaria con mucho éxito en los países en desarrollo, aunque el adoptar dicha figura constituye un interés mayor en tales naciones" ${ }^{15}$ A pesar de dicha renuencia, cada uno de los paises de América Latina ha ido introduciendo la figura en sus diseños constitucionales y, para cllo, imita, en gran mexlida, la disposicion nom ativa española. En Paraguay se tata del "defensor" vecinal de Asunción"; cn Chile, del "presidente del capítulo chileno del ombudsman", similar nombre al que asumió en Bolivia: "capitulo boliniano del ombudsmon". En Houdurras, México y Guatemala se insistió en la problemática de los derechos humanos; así, en el primer caso, el ombudsman es el "comisionado nacional de protecrión de los derechos humanos"; en México es la Comisión Nacional y en Guatemala, un "procurador" que defiende esos derechos, similar calificativo al que ha recibido el ombutsman de El Salvador. Fn Costa Rica, el ombudsman se denomina "defensor de los habitantes de la República"y en Argentina, "defensor del pueblo". En la actualidad, los 39 países de la región de Anérica Latina y el Caribe tienen nás de 20 mbudsman en el nivel nacional y una gran cantidad de organismos estableciclos en los estados organizados bajo modalidades federativas (México), en provincias (Argentina) y en e] nivel municipal. No todos los Estados, sin embargo, han evolucionado al nismo ritmo. De las 70 instituciones de este género existentes, más de 30 son mexicanas y casi 20 , argentinas. En México, y de acuendo con nuestros datos, el procuradon de protectión ciudadana está en funciones en el estado de Aguascalientes; el procurador de los derechos lummanos y protección ciudactana lo hace en Baja California y Guanajuato, y el presidente de la Comisión de Defensa de Derechos Humanos se halla inserto en cl resto de los estados. ${ }^{16}$ En Argentina, por su parte, unas 10 provincias cuentan con defensores del pueblo, quienes son superados en númem por los defensores de

\footnotetext{
${ }^{14}$ Jorge Santistevan de Noriega, “Capitulo latinoamericano y del Catibe. Informe negional, I\$96. 1997", en Defensurín de Perú, http://ombudsman.gob,pe; hetp//www,lak.ualherta.ca/centues/iol.

is Dunald Rowat, "Preface to second edition", en Donald Rowat foomp.), The Ondadswen, Cutizen's

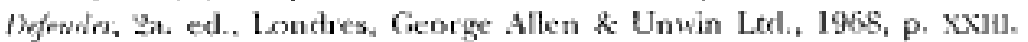

Je Ellow son Baja Califomia Sur, Campechr, Coahuila, Colima. Chiapas, Chiluahua, Diverito feclent, Durango, Estadu sle Méxio, Gucrero, Hidalgo, Jalisco, Michoacán. Morelos, Nayarit, Nuevo Lán,
} 
ciudades. ${ }^{17}$ La elevada canticlad demuesta que ambos países contienen los sistemas de ombudsman más grandes qque operan en América Latina, y quizás en el mundo; por ello, merecen que se corra el telón y se les estudie detalladamente para contrarrestar la ceguera con que los científicos sociales han respondido a la aparición en escena de esta peculiar institución.

En la segunda mitad del siglo xx el ombudsman se convirtió en una figura al servicio de las ciencias y de los Esiados, en un actor fundamental en la redefinición de los vínculos entre la ciudadanía y la administración, y en el caballito de batalla de la moderna ciencia política que le atribuye capacidad de control no jurisdiccional. Dichos problemas son, en apariencia, competencia directa de las ciencias estrictamente juridicas pero, como vertemos, la lectura e interpretación antropológica e histórica resultan esenciales para comprender no tanto la funcionalidad de la oficina del ombudsmon como su indole en el marco de la definición del Estado y de sus instituciones. Para muchos de los especialistas en la defensoria, su rol genérico es ponerse en posición intermedia entre los intereses del Estado y de los ciudadanos, con la finalidad de compensar una inadecuada administración. Lo cier to es que no desempena funciones de juez, ni fiscal y, en consecuencia, no dicta sentencias, no ordena detenciones ni impone multas. Su poder descansa en la persuasión, en formular estrategias de protección preventiva, en la mediación que asume para encontrar soluciones y en su capacidad de denuncia pública en casos exrremos. De tal manera, absorbe las quejas que los ciudadanos presentan contra la administración pública, investiga los casos planteados y recomienda posibles transformaciones legislativas al Congreso. En tanto organismo tutelador de los derechos humanos y encargaclo del control de las funciones administrativas públicas, el ombudsman supone una garantía constitucional para limitar, con base en ideas de justicia social, toda posible determinación juridica que se oponga a dichos postulados. Se rata de uno de los ejes centrales de este artículo.

Algunos autores lo han calificado de "magistratura de opinión", mientras otros sostienen que es un referente básico del constitucionalismo modemo en el marco del nuevo sistema de relaciones entre ciudadano y administración en el Estado denocrático. Donald Rowat, uno de los más conoc idos difusores de la institución en el munclo académico, afirma, por' su parte, que el ombudsman debe ster considerado como un componente esencial para la armonía del gobieno democrático. La institución -señalan los especialistas-ayudaría a encontar soluciones a los problemas de la burocracia en el mundo democrático con la legitimidad que le ha concedido Bexelius.

Oaxaca, Pucbla, Queretaro, Quintana Roo, San Luis Potosí, Sinaba, Sonora, Tabasco, Tarmaulipias. Thaxcala, Veracruz, Vucatán y Zacatecas. En Jorge Santistevan de Noriega, "Capítulo larinoamericano y del Caribe. Informe regional, 1996-1997", en Dgfensoria de Peri, http:/ ombudsman.goh.pe.

If Las provinctas de Córdoba, La Rioja, Salta, Sin Juat, San Luis, Rio Negro, Formosa, Santa Fe, Tucunnán y, en el régimen municipal, se cuenca con los ckefensores del ciudaclano de La Plata, Mar del Plata, Buenos Aires, Posadas, Chilecito, La Rioja, La Banta, Santiago del Estero, Río Cuarto, Arroyo Seco, en Inforzues antules del defensor dd puetio de la vación angentina al honoratle Congres de in nacrón: primeto, del 17/10/1994 al 31/12/1994, tomo I; scgundo, det 01-01-1995 al 31-12-1995, tomo 11 . p. 149. 
esto es, su calidad de organo representativo del Parlamento y, "por ende, de los ciucladanos". ${ }^{18}$ En este artículo estudiamos la vinculación directa que hace Bexelius, y que comparten los especialistas, acerca del grado de representatividad del ente legislativo y de su órgano de contralor corporizado en el ambutsman: lo hacemos mediante: el análisis del caso sustentado por cl defensor del pueblo argentino desde los primeros días de asumir su cargo, con un negocio cuyas ganancias anuales son estimadas tu más de 10000 millones de dólares anuales. Nos referimos al conflic to sostenido con las empresas monopólicas del país que controlan el servicio telefónico, cuva particularidad no le quita validez para rediscutir los argumentos jurídicos abstractos en tonno a la indole de la institución. De manera paralela, analizamos dos conceptos clave en los discursos del defensor argentino: justicin socialy justicia legal, en relación con las demandas de los ciudadanos y con las respuestas de la administración pública. Planteamos también nuestras hipótesis en tomo a las estrategias de resolución opcional cle conflictos, resignificadas por el ombudsman, y al papel que debe desempeñar este úlimo en las sociedades latinoamericanas, las cuales se hallan inmersas en un conflictivo y discontinuo proceso de democratización política.

\section{II . El. PROCESO PRIVATIZADOR Y LA PROTESTA CIUDADANA}

La institución del defensor del pueblo de Argentina tiene origen en el cambio consfitucional del año 1994 y abrió sus puertas con gran expectación por parte de una población deseosa de encontrar canales de resolución a conflic tos distintos clel jurisdiccional, pero también con la confianza que le daba la pertenencia de su titular al partido político en el poder. En efecto, el priner mbudsman nacional, el abogado Jor ge Luis Maiorano, se había desempeñado hasta la reforma de la Carta Magna como ministro de Justicia del líder del pas tido justicialista (peronista), Carlos Menem, y había sido asesor de su valedor político y hermano det presidente, Eduardo Menem. I a tiarlaridad del ombudsman le fue concedida por razones partidarias y políticas pero también académicas, ya que su tesis doctoral en Derecho se centró en las estrategias de control administrativo - el sector del ordenamiento juridico que regula la organización y el funcionamiento de la administración pública- y en la importancia concedida al ombudsman como opción ante el feroz crecimiento burocrático europeo. Maiorano fue elegido comisionado del poder legislativo con las clos terceras partes de

15 Alfied Bexelies, "Sweden's guardians of the law: The ombudsman of civil affairs", en Dogald Ronat (comp.). The Ondbudsman, Citizen's Defende, 2a. ed., Londres, George Allen \&. Unwin Ltd., 1968, p. 24, nota. También Donalet Rowat, "Preface to second edition", en Donald Rowat (comp.), The Ombidsman, Citizen's Dgender, 2a. ed., Londtes, George Allen \& Unwin 1.td,, 1968, p. v; Alvaro GilRobles y Gil Delgado, "Filosofía del defensor del pueblo`, en Paloma Biglino Campos (comp-), Et trocurador del comén: defensor ded pueblo y coununidades autónowas, Joruadas de Estudio, Valladolid, Iniversiclad de Valladolid, 1995, p. 32. Margarita Retucto Buades, "Ámbito propio diel defensor del pueblo y relaciones de coordinación y cooperación con los órganos șimilares de las Comunidades iutonomis", en Paloma Bigtino Campos (comp.), El fracurador dé común: defensos dé pudbo y coinunidodes autönoxns Jounadas de Extudio, Vallaclolid, Universidad de Valladolid, 1995, p. 97. 
Ios votos de las cámaras de diputados y de senadores (el mínimo exigido constitucionalmente), aunque no contó con el apoyo de los partidos de la oposición. ${ }^{19}$

Al diferenciar cada uno de los ámbitos de actuación del defensor del pueblo argentino se advierte que casi dos terceras partes de las quejas recibidas han estado vinculadas con aspectos económicos, de empleo y seguridad social (cuadro 1). En el priner caso, es decir, en el campo de la administración económica. la defensoria ha estado encaminada a dar respuesta a las quejas planteadas por los usuarios de servicios públicos contra la deficiente prestación de éstos. Asi, $40 \%$ de las quejas se referia a problemas vinculados con la ciudadania en calidad de ustaria y consumidora; indice indicativo, por otra parte, de la existencia de un tímido movimiento de consumidores que intenta vigilar al Estado, contrarrestar los efectos de su retracción y limitar los riesgos que supone la dependencia de compañas que, al carcer de competencia, imponen a sus usuarios decisiones unilaterales y arbitrarias.

\section{CUADRO 1}

ARGENTINA EN PORCENTAJE:

EL OMBBULSHAN EN SLIS INFORMES A LA LEGISLATURA

\begin{tabular}{|c|c|c|c|c|c|c|}
\hline Arens de administracions & 1994 & 1995 & 1946 & 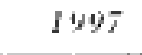 & 1998 & nis sublotairs \\
\hline Económica & 39,00 & 33.79 & 31.69 & 40.10 & 44.50 & 37.86 \\
\hline De empleo y seguridad social & 25.30 & 35.50 & 43.00 & 28.80 & 23,10 & 31.10 \\
\hline De justicia y detechos humanos & 24.55 & 14.00 & 10.80 & 13.00 & 13.80 & 15.30 \\
\hline Sanitariat y acción social & 4.80 & 10.40 & 5.90 & 8.40 & 10.40 & 7.98 \\
\hline Cuitural $y$ inedio ambiente & 6.50 & 6.30 & 8.60 & 9.40 & 8.00 & 7.76 \\
\hline Total de actuaciones & 756 & 7256 & 22697 & 25496 & 30434 & $805639: 100 \%$ \\
\hline
\end{tabular}

FLENTES: Elaboracjön propia a partir de los Informes anuale del defener del pudVo de La nacion argentina al honowlle Congreso de la nación Primero (1994) del 17/10/1994 al 31/12/1994, 3 vols.; Segundo (1995) 3 vols.; Tercero (1996) 2 vols.; Cuarto (1997) 2 vols.; Quinto (1998) en http:// defensor.govar. Para el puimer año, las causas van del 17-10-94 (fecha de puesta en funcionamiento de la oficina) al 31-12-94.

iv Simbito Fianacien, 31-05-1995, p. 12. Conferencia pronunciada por Jorge Luis Maiorano en la sede del Instituto Catalán de Cooperación fbetoamericana, julio de 1998, Barcelona; Disurso del presidente provisional del honorable Congreso de la nación, Eduardo Menem, 17-10-1994, en Prime Infonte Awtual, tomo 1, Pp. 506-63. Jorge Luis Maiorano, El owbudsmen, defensor del pudto y de los

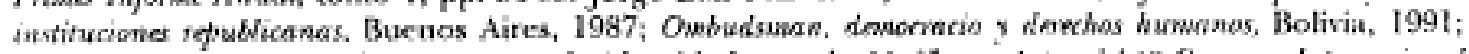

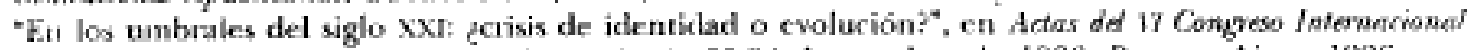
ded Institito Internacional Sel Onbudswan (101), 20-94 de nciubre de 1996. Btienos Aires, 1996, Pp. 59-66. 
En el campo de la administración del empleo y la segunidad social, por su parte, los trămites previsionales de personas de avanzada edad, jubilados y peisionados, contribuyeron a engrosar el elevado porcentaje, en un total de casi 90000 quicjas prescutadas dt: 1994 a $1998 .^{.0}$

La "representación" de tipo informal que ejerce el defensor del pueblo de Aigentima en relación con la ciudadanía le ha exigido mediar en las relaciones con las empresas licenciatarias que han convertido a los usuarios en población "cautiva" de los servicios que ellas controlan en términos monopólicos. Esta atribución de la oficina fue justificada con el argumento de que lograría estimular lat par ticipación de la sociedad civil en la gestión de: los asuntos publicos; asimismo, humanizaría las relaciomes entre el individuo y el Estado al dar "voz a los que no la tienen y no pueden llegar a los medios de control". Dicha estrategia responde, en realidad, a la intención de la institución de ganarse la confianza de la comunidad mediante el prestigio, y de transformar a los ciudadanos y a los grupos intermedios en "sombras éticas del poder"."I

Uno de los casos más significativos y representativos de la defensoría fue el que involucró de 1994 a 1996 a las empresas monopólicas concesionarias del servicio relefónico que funcionan bajo licencia estatal, o sea, las socicdades anóninas Telefónica de Argentina y Telecom Argentina Stet-France, que en octubre de 1994 acordaron con el poder Ejecutivo la elevación de los precios del servicio. El objetivo de sste proyecto cra bajar el costo de las llamadas cle larga clistancia e internacionales y subir el valor de las comunicaciones urbanas. Para la zona de la capital y Gan Buenos Aires, dicha medida significaba, de acuerdo con el programa originario, el ammento pronedio de las llamadas urbanas en 30\%, y alzas puntuales para el Gran Buenos Aires que llegabau a $200 \%$. La rebaja para las llamadas interurbanas (larga clistancia nacional) iba de $2 \%$ a $54 \%$, y en las internacionales, de $8 \%$ a $66 \% .2$ Fstos indices futron calificados de "retbalanceo".

Refractaria a asumir tal ajuste, la entidad Acción del Consumidor (Adelco) bamitó una actuación de amparo ante el Juzgado Nacional en lo Contencioso Administa ativo de la Capital Federal contıa la Secretaría de Obras y Servicios Públicos, y acusó directamente al Estado nacional de desconocer la oblignción de presentar informes técnirosy jurídicos justificatorios de la restructuración tarifaria (Actuación 247/94). Adelco se opuso al rebalanceoy, apoyada de manera unánime por la ciudadanía y los par tidos de la oposición, promovió el juicio a fin de que el tribunal ordenara la realización de unit audiencia pública para permitir la participación de todos los actores involucrados. Como vemos, este caso empezó por aglutinar en torno a sí a tres agentes intimamenté relacionados en los debates sobre las relaciones entre Estado y ciudadania; nos referimos a las compañias concesionarias, al poder político (Ejecutivo y Logrislativo) y a los

5o La Raxorn, 12-07-1995, p. 8.

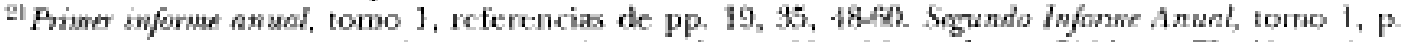
xxxII; tomo II, p. 905. Cranto hyforme Ansal, tomo 1, pp. 11 y 13. Anthony Gididens, The Naten-Stalo

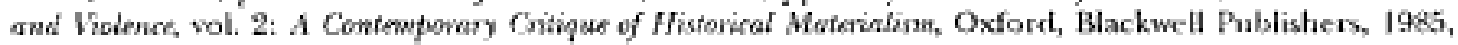
p. 318 .

ล. Cerrin, 27-09-1995, p. 33. 
ciudadanos previstos, al menos en este ámbito, en su calidad de consumidores en torno a Adelco, la cual entendía que la modificación tarifaria no podía celebrarse a espaldas de los interesados, y que era necesario dar la posibilidad a todos los agentes de exponer sus puntos de vista para intentar encontrar una solución conjunta y satisfactoria tn términos colectivos. Para ello, un cuarto espacio institucional hizo acto de presincia: el poder no político e independiente en la estructura estatal, el jurisdiccional. que aceptó la solicitud de Adelco de detener el acuerdo tarifario que se encontraba en trämite. Ahora bien, un quinto agente entró en escena por primera vez en Augentina en cste tipo de debates. Adelco citó al ombudsman en calidad de tercero interesado, pero el defensor rechazó el carácter obligatorio de la citación y argumentó que una de las caracteristicas fundamentales de la institución es que no prede ser obligada a participar en procesos judiciales, sino que su actuación incumbe sốlo a su propia determinación y juicio para garantizar la independencia de la oficina. Como informó Maiorano, "ninguno de los órganos del Estado, así como ninguna institución pública o privada o particulares, pueden obligarlo a constituirse en parte y litigar".

A pesar de poner esta condición, y quizá creyendo que contaría con el apoyo del poder Ejecutivo por su demostrada fidelidad política, a los pocos días de asumir su cargo, el ombudsman argentino se embarcó en un largo y agotador debate con las empresas telefónicas. Comenzó por aconsejara los usuarios no pagar el servicio hasta tanto el caso fuese restuelto, y se dirigió a la Comisión Nacional de Telecomunicaciones (CNT), organismo regulador del cual dependian las telefónicas, para solicitarle un informe sobre la legitimidad y necesidad del cambio tarifario. La CNT opinó desfavorablemente sobre los argumentos del gobierno; Adelco y el defensor del pueblo, por su parte, exigieron la realización de dos audiencias públicas con la participación del Ministerio de Econonía y de Obras y Servicios Públicos de la Nación, actitud que fue acompanada de la decisión de la justicia de paralizar lo que se conoció por entonces con el calificativo de "telefonazo", csto es, la subida desmedida e injustificada de los valores impuestos a los ustuarios. Para reforzar su posición, el defensor solicitó información sobre la identidad de los funcionarios que habían intervenido en la definición del nuevo esquema tarifario; para ello argumentó posibles irregularidades en el pacto y, muy pronto, declaró que consideraba importante esta acción para el "posicionamiento del órgano de control ante la sociedad ${ }^{n} .9$

Paralelamente a la publicidad del recurso judicial de no innovar en el rebalanceo tarifario hasta consensuar la medida entre la población y el resto de los agentes en juego, la prensa se hizo eco de los debates, los cuales dispararon una reacción en cadena. El Ministerio de Economía se vio obligado a convocar y presidir las audiencias públicas reclamadas. E1 21 de noviembre de 1994 se efectuó la primera en la ciudad de Buenos Aires, y en ella los directores de la CNT rechazaron explicitamente la restructuración tarifaria propiciada por las licenciatarias telefónicas y el gobierno,

4s Diario Clnin, 01-11-1994; 02-11-1994; Ambeto Financiero, 02-11-1994; Pagina 12, 09-11-1994; Chónice, 02-1 1-1994; 05-11-1994; Custo inforwe anant, tomo I, p. 8. 
actitud reiterada durante una segunda instancia practicada en la ciudad de Mendoza un mes y medio después. En vista de la imposibilidad de convertir su proyecto en hegemónico, el Ejecutivo dejó temporalmente a un lado el rediseño acordado con las empresas, a pesar de que el propio presidente de la nación expresara en numerosas oportunidades su beneplácito por el plan de subida de precios. Paralelamente, el defensor intimó a las telefónicas a entregar datos sobre tráfico de llamadas y costos, y el gobierno reaccionó con la proposición, en contraparticla, de contratar una consultora extranjera. ${ }^{24}$ En el mes de mayo del año siguiente, con escasas perspectivas de conseguir apoyo institucional y popular, y dada la disidencia de la Comisión Nacional de Telecomunicaciones, el poder Ejecutivo decidió intervenir por decreto la CNI; así pues, dispuso el desplazamiento de su directorio (el cual habia sido elegido por concurso) y nombró un interventor con la excusa de que había informes negativos brindados por la consultora británica NERA. La arbitraria decisión gubernamental fue valorada como un atentado contra las propias bases constitutivas del organismo, las cuales establecían que los directores sólo podían ser retirados de su cargo mediante dictamen acusatorio y procesos sustanciados por la Procuración del Tesoro. La reacción de la Legislatura fue inmediata y, por unanimidad, la Cámara de Diputados solicitó informes al poder Ejecutivo. Si pensamos en la situación actual en que se encuentra Venezuela, con su Congreso disuelto por los continuos embates del gobiemo y con su poder judicial permeado completamente por el espíritu dictatorial de aquél, la actitud de la Cámara de Diputados argentina - así como del órgano sin poder con fuerza vinculante que es el ombudsman-adquiere mayor trascendencia por su posibilidad o imposibilidad de limitar al Ejecutivo. En este sentido, la Comisión Bicameral del Parlamento para el Seguimiento de las Privatizaciones (que controla la aplicación de los pliegos de privatización de la antigua compañía telefónica nacional ENT el) se pronunció por declarar nulo el decreto intervencionista y recomendó restituir en sus cargos a los directores de la CNr desplazados por decreto. El defensor del pueblo amenazó también con presentarse ante la jurisdicción contencioso-administrativa federal si uo se retrocedía en la intervención del organismo. Ahora bien, en esta oportunidad la reacción popular e institucional pareció pasar inadvertida para el gobierno. El Ministerio de Economía se negó a restituir en sus puestos a los directores legítimos y. para agravar la situación, con el transcurso de los clías trascendió que la consultora no sólo no había rendido su dictamen, sino que ni siquiera había sido contratada, como había sugerido el decreto. ${ }^{25}$ Cuando lo hizo, tres meses después de estos hechos, el diagnóstico resultó negativo en relación con la legalidad y necesidad del nucvo plan tarifario. ${ }^{26} \mathrm{El}$ proyecto más global del gobiemo era, en realidad, fusionar la Sub-

24 Ámbito Financiero, 27-09-1995, p. 3; Clarin, 27-09-1995, p. 33.

${ }^{35}$ Sobre el significado y la utilización de la prueba, efr. Silvia Gómez i Mestres, "La prueba. El suplicio de la certeza", en Iguasi Terradas i Saborit (coord.). Antropologio juridiea, Santiago de Compostrla, 1999. pp. 55-67.

${ }_{25}$ Por otra parte, se corrió el rumor de que el interventor propuesto por el Ejecutivo había sido, achernás, clesignado subsecrerario de Combustibles, es decir, condensaba en torno a sí dos cargos de diversa indole y competencia. 
secretaría de Comunicaciones de la Secretaria de Obras Públicas a la de Energía, presidida esta última por un director completamente confiable para el Ministro de Economía. Al hacer frente a esta suma de irregularidades y arbitrariedades, el defensor del pueblo decidió cumplir con su promesa: acudió a la justicia y solicitó la nulidad y declaración de inconstitucionalidad del decreto de intervención, así como "el restablecimiento del orden jurídico violentado". La intervención del Ejecutivo contra el ente regulador, afirmó, apuntaría directamente al desmantelamiento del organismo de contralor cuya tarea es tutelar los derechos de los usuarios del servicio de telefonía básica, índole jurídica que comparte de manera implícita con el propio ombudsman. Permitir intervenciones de este tipo haría "poco creible" la gestión de los órganos de control y transformaría a los entes reguladores en meros onganismos estéticos. El defensor colocó a la seguridad jurídica en el centro del debate y propuso una primera diferenciación argumental entre la legalidad garantizada por el orden jurídico, y la seudolegalidad impuesta por la violencia y discrecionalidad del poder Ejecutivo:

El decreto, en cuanto decide intervenir a la CNT. es ilegal, prues carece de causa que lo justifique y además es anbitranio, por lo cual resulta nulo de nulidad absoluta, en los términtos del artículo 14 de la Ley Nacional de Procedinientos Administrativos [...] los directores con versación en materia de telecomunicaciones denunciaron anomalías respecto de la recomposición tarifaria propiciada entre octubre y noviembre de 1994, que parecía contar con el beneplácito del Ministerio de Economía nacional [...] La intervención de Ls CNT, sin motivos, o mejor dicho, con fundamentos falsas, tendrá consecuencias mucy graves, pues sienta un precedente de inseguridad juridica para las entes reguladores: parece que. cuando sc. adoptan decisiones con las que no se concuerda, se resuelve arbitrariamente una intervención. ${ }^{27}$

Es importante señalar que, a esta altura del conflicto, se condensó nuevamente la participación de todos los agentes que hemos venido reseñando hasta ahora, a excepción de Adelco, cuya presencia pareció diluirse de manera paulatina al compás de la hegemónica presencia de los diversos poderes (jurisdiccional y políticos) y autoridades (el defensor del pueblo). ${ }^{28}$ Concluir con el relato de este caso nos facilitará replantear el significado de la defensoría en el seno de los vínculos entre justicia legal y justicia social, en torno a la oposición entre legy justicia, y en relación con el ejercicio de contralor sobre los diversos poderes que componen el organigrama estatal. A finales de julio de 1995 la justicia de lo contencioso-administrativo declaró nula la intervención de la CNT, quitó legitimidad al interventor designado por el Ejecutivo y utilizó para ello los argumentos brindados por el defensor, a saber: la arbitrariedad del decreto por carencia de fundamento. Refutó el argumento esgrimiclo por el gobierno de

27 Referencias de Página 12, 08-06-1995, p. 12: 28-06-1905; Ámbito Financiero, 05-06-1995, p. 9; 0;06-1995, p. 4; 09-06-1995, p. 6; cita extrafda de 08-06-1995, p. 8, cursivas nuestras; 20-07-1995, p. 8; 27-09-1995, p. 3; 28-08-1995, p. 9; 28-11-1995, p. 9; 20-01-1996, p. 5; La Nación, 26-09-1995, p. 3.

29 Por medio del diputado socialista Héctor Polino, sin embargo, se articuló una especie de organización denominacta Consejo de Administración de Consumidores Libres, Cooperativa Limitada de Provisión de Servicio de Acción Comunitaria, en Áwbito Financiero, 20-07-1995, p. 8; La Nación, 2007-1995, p. 3. 
que la intervención era un acto privativo y discrecional del poder Ejecutivo que no debe ser sometido a revisión por parte de la justicia, y sostuvo que los actos administrativos, al igual que los decretos, "tienen límites jurídicos que permiten el control judicial" si entran en conflicto con tas disposiciones que marca la ley. Habiendo perdido en la primera instancia, el gobierno apeló la clecisión judicial y, paralelamente, el defensor del pueblo requirió al Juzgado de lo Contencioso Administrativo federal la orden de convocatoria a una nueva audiencia pública antes de tomar una decisión final sobre las trifías telefónicas. Por primera vez presentó una acción de amparo contra el Estado nacional (confornado por el Ejecutivo, el Ministerio de Economía y Obras y Servicios Públicos) para bloquear los cambios en el cuadro tarifario.

Llama la atención [señaló el ombudswan] que el Ministerio de Econoniá intente apartatse del criterio seguido anteriormente en cuanto a la realización de una audiencia pública y que pretenda una modificación de tarifas telefónicas sin la participación de las cntidades representativas de ustarios. La audiencia píblica debía funcionar, en este contexio, como una instancia politica de debate así como para tratar de frenar a las autoridades en sus pretensiones ilegítimas. ${ }^{29}$

\section{III . LA DEFINICJÓN DEL CIUDADANO EN TÉRMINOS DE RSTTCA SOCJA: ¿ADMINISTRADO, CONTRIBUYENTE O USUARIO?}

A un año de la polémica por la restructuración de las tarifas, y en el aniversario de lat creación de la defensoría, la prensa comenzó a debatir dicho caso en términos de: oposición entre lo legaly lo legítimo, binomio utilizado también por el ombrulsman con base en criterios sociales. Este último aprovechó didácticamente tal conflicto para informar a la ciudadanía acerca de la indole de la institución a su cargo mediante las decisiones puntuales tomadas en torno a la polémica mantenida con el presidente de la nación, el Ministerio de Economía y las empresas monopólicas. El caso mencionado despertó gran interés en los medios de comunicación entre 1994 y 1996; dado su carácter ejemplificador sobre el rol que ocupa el poler Ejectitivo en Argentina, resulta representativo del modus tivendi de las instituciones. Refleja también los resultados conflictivos del proceso privatizador que afecta a la economia del país en los últimus años y que ha colocado a la ciudadanía en una situación de gran indefensión frente at las corporaciones extranjeras (a mediados de 1999, por dar un ejemplo, la petroletat espanola Repsol adquirió la única y última empresa rentable, Yacimientos Petroliferos Fiscales, a un precio inferior al esperado). ${ }^{30}$

So Ámbito Financiero, 20-07-1995, p. 8; 27-09-1995, p. 3; Clarin, 97-09-1995, p. 32; Cuarto Pesies, 28-09-1995, p. 24 .

50 Las ganancias de estas túltinas, por otra parte, no son pingües. lin el caso de las telefónicas que operan en Argentina, durante el ejercicio 199+1995 Telecon y Telefönica facturatun casi 4000 millones de dólares. La Nución, $2809-1995$. p. 4. 
A este clima enrarecido por la interpelación al gobierno se sumó el economista juan Alemann, quien acusó al defensor del pueblo de desconocer los contratos de concesión firmados entre el gobierno y las empresas que establecían el reajuste tarifario como condición sine qua non de la existencia del pacto. "Recordemos que un buen sistema jurídico que se cumple a rajatabla [afirmó Alemann] es la base de todas las economías modernas. Los países que no tienen orden jurídico son subdesarrollados, por más recursos que tengan, simplemente porque en ellos no se puede invertir." Cumplir los contratos, más allá de los efectos sobre las personas, pareció ser el corolario de esta argumentación, tan liberal como contraria a los postulados de justicia social ponderados por el defensor. Dicho diálogo fue permeado por la publicidad de un dato central en este debate: la consultora NERA, mediante su informe escrito en lengua inglesa, adujo que, de haberse aplicado la restructuración tarifaria originaria del año 1994, un año después las empresas licenciatarias hubiesen obtenido 500 millones de dólares de ganancias adicionales en lugar de la reducción de los ingresos totales que prometía el Ministerio de Economía. Similar situación se detectó en otros servicios recientemente extraídos de la égida estatal y monopolizados por licenciatarias privadas, esto es, la prestación de servicios públicos domiciliarios (energía eléctrica, agua y gas) y no domiciliarios (concesiones de peaje de transporte). Dado que la decisiốn sobre tarifas es privativa del Ministerio de Economía, las esperanzas de los medios de comunicación, de los partidos de la oposición, de la ciudadania y del defensor del pueblo fueron depositadas en el rechazo público más o menos unánime contra el reajuste más que en el apoyo del gobierno; pero la decisión jurisdiccional de segunda instancia comenzó por destruir tales ilusiones, ya que a finales de octubre de 1995 la Cámara de Apelaciones revocó el fallo dictado por el juzgado de primera instancia y convalidó la intervención de la $\mathrm{CNT}$ dispuesta por el poder Ejecutivo. El argumento judicial fue la legrtidad de la disposición ejecutiva. En una entrevista concedida al Suplemento Nueva Justicia (el hecho resulta más que irónico) del periódico Ámbito Fünanciero, el ombudsman apuntó que era necesaria una loy justa para ser declarada legítima:

Se puede dar el caso de que existan las vias legales para que se opere un incremento o rebalanceo de las tarifas; será legal. Pero dificilmente puede llegar a ser legitimo en el marco de la realidad que diariamente nos habla de reducciones presupuestarias, elevado porcentaje de desempleo, rebajas de salarios congelados desde hace anos, frente a empresas que han tomado los servicios telefónicos en todo el país con carácter monopólico y que anuncian a los cuatro vientos ganancias de cientos de millones por años. $^{s 1}$

${ }^{31}$ Cita de Ambito Financiena, Suplemento Nueva Justicia, 12-12-1995, p. II. Referencias de La Razon, 02-10-1995, p. 5; 04-10-1995, p. 12; 19-10-1995, p. 24; Ambito Financiero. 10-10-1995, p. 18; Cuarto Poder, 10-10-1995, p. 22; 03-11-1995, p. 24; Página I2, 13-10-1995, p. 10; 21-10-1995, p. 7. 
El flujo de los conceptos coincide en un principio general encontrar la justicia para los usuarios y consumidores, como si esa justicia estuviese, al menos en este caso concreto, fuera de la ley y no alcanzase el calificativo de "legal" para asegurar su legitimidad. En este contexto, el defensor cuestionó directamente la legalidad del proytcw de gobierno con base en el principio de justicia social y afirmó que "algunos funcionarios piensan y pretenden seguir actuando como patrones de estancia", y lo hacen encubriendo la ilegitimidad bajo neologismos como "recomposición", "restructuración" y "redimensionamiento". ${ }^{32} \mathrm{Si}$ hemos seguido atentamente la evolución del caso, es posible comprobar que esta categoría de justicín social reincorporó al debate la dimensión humana para compensar su ausencia real en el conflicto. El defensor del pueblo de Argentina definió el concepto y el ámbito de la justicia bajo el sencillo esquema de "dar a cada uno lo suyo". Este debate circunscribió su accionar en el caso planteado y, en térnninos generales, puso en tela de juicio la propia definición del Derecho:

Más allả de que el pretendido aumento de tarifas telefónicas prueda ser legal, tema que merece un profundo análisis, la pregunta que todos debemos hacernos es si resulta legítima. Legíumo no sólo en cuanto a los porcentajes, sino también respecto de los procedimientos. Legitimo frente a las reducciones salariales a los jubilados y pensionados que están cobrando sus haberes casi nun mes más tarde; a la desocupacion y a la situación sacial. Ante esta realidad de la gente, vemos periódicamente anuncios de sustantivos resultados económicos para las prestatarias del servicio, merecidos en tanto se han ejecutado importantes avances en la materia, pero francamente irritantes para la realidad de millones de personas, la mayor parte de ellas clientes cautivos de esas mismas compañias. No creo lógico ni prudente que se siga invocando aquí lo legal por sobre lo legitimo. ${ }^{\text {s9 }}$

Estas diferenciaciones de carácter subjetivo deben hacemos penar en las adjetivaciones con que suele recubrirse el vocablo justicia. Hans Kelsen afirma que, ante una situación de desorden, se utilizan convenciones de justicia que, a su vez, se sostienen por un criterio de validez. El autor conviene en que se trata de un concepto vacuo sustentado en juicios de valor, como puede ser la confluencia del "deber ser" con el "es", para que lo que "es" sea inmanente a lo que "debe". En esta operación de convergencia entre lo real y lo ideal, la pretensión del Derecho es presentar la norma escrita (el derecho legal) como un ente inaluerable e inmutable, y negar - de manera paralela-la relatividad e historicidad de los juicios de valor. Pero el proceso de racionalización del Derecho se activa cuando se ponen en juego conflictos de valores; es entonces cuando se manifiesta la relatividad de los intereses en juego, aun cuando la justicia que podemos calificar de legal pretenda definir lo que es justo en términos absolutos con el objetivo de conciliar las necesidades contradictorias de estabilidad y adecuación al caso concreto ${ }^{84}$ La justicia sacial, por otra parte, adquiere un rol central en el escenario de

se La Rnzón, 29-09-1995, p. 6.

ss La Razón, Buenos Aires, 29-09-1995, p. 6, cursivas nuestras; La Opinion Austral, 14-10-1998, Santit Cruz.

${ }^{4}$ Hans Kelsen, ¿Quet es justicia?, Barcelona, Ariei, 1989; Roscoe Pound, Las grandes tendencins dé pensantiento juridies, Barcelons, Arie1, 1950, p. 5. 
las demandas que, en ocasiones, son contrarias a la definición legal En nuestro caso, el defensor redefinió la validez y legitimidad del ámbito de lo legal mediante argunentos metajurídicos y en función de la apelación al caso concreto. Si seguimos este recorrido argumental, lo legítimo, si triunfase, debería hacerlo por sobre la ley concreta, perspectiva no aceptada fácilmente por el Derecho positivo. En el caso concreto que nos ocupa, se advierte la colisión entre la norma y las expectativas de las personas, entre: la concepción de lo que es legal y de lo que es socialmente justo. Nos encontramos frente a un instituto que pondría en tela de juicio la propia concepción del Derecho y de la lev.

La tercera audiencia pública organizada nuevamente por el Ministerio de Economía a finales de enero de 1996 congregó a las telefónicas, a los funcionarios afectados, a los representantes de los usuarios y al defensor del pueblo. Estos dos últimos agentes se opusieron a cualquier tipo de incremento, y fueron contrarrestados por los dos primeros que consensuaron el cambio aun sin hacer explícitos los niveles de ganancia reales que supondría para las empresas y el costo para los usuarios. Este acuerdo fue el mismo que intentó imponer el gobiemo más de un año antes, y que había sido rechazado por el ombudsman y las asociaciones de consumidores. En un contexto adverso, Maiorano decidió informar a la población de las verdaderas razones que llevaban al gobierno a apoyar a las licenciatarias, y que estaban relacionadas con su intención de que éstas pudiesen quedar en mejor posición frente a la futura apertura de la competencia en la telefonía básica. ${ }^{50}$

En 1996, pasado ya más de un año de debates entre el poder Ejecutivo, la defensoría del pueblo, las empresas monopólicas y la ciudadanía, el gobierno decidió cambiar la jurisdicción de la Secretaría de Comunicaciones, hasta entonces dependiente del Ministerio de Economía y Obras y Servicios Públicos, a la presidencía de la nación, y logró imponer así la tan cuestionada restructuración tarifaria sin tomar en cuenta la posible disidencia del poder Legislativo y del ombudsman. Si algo quedó claro en el conflicto analizado fue la índole de la actuación del defensor frente a la percepción de injusticia generada por la coalición entre el Estado y las empresas monopólicas, actuación sin poder y sin capacidad real de "defender al pueblo" cuando los propios órganos que deben aceptar sus recomendaciones deciden hacer oídos sordos. En la última audiencia realizada en el norte del país, en la ciudad de Posadas, el defensor criticó la decisión unilateral del Ejecutivo, advirtió acerca de los efectos de pérdida de legitimidad y de credibilidad del Estado frente a la ciudadanía y se preguntó claramente: "¿A dónde irá a parar la credibilidad de la sociedad en un modelo que ha hecho de las privatizaciones y concesiones una política permanente, pero al cual le está quitando uno de sus soportes fundamentales: el indelegable control del Estado y la participación ciudadana en ese control?". $\$ 6$ Los "usuarios cautivos" de los servicios públicos del país, agregó, merecen que se controle tanto a los organismos guberna-

\footnotetext{
\$ Jorge Luís Maiorano, "La verdad a medias es la peor mentia", La Rezón, 09-02-1996, p. 6; Aunfato Finaneimo, 01-02-1996, p. 7.

3. La Razin, 20-12-1996, p. 28.
} 
mentales encargados de la regulación de esos servicios como a las empresas concesionarias, y que se modifiquen las leyes injustas en mérito a las disposiciones constitucionales que aseguran el respeto a los derechos humanos, ${ }^{37}$ haciendo referencia indirecta tanto a los derechos de segunda generación (sociales, económicos y culturales) como a los de tercera generación, esto es, los derechos colectivos, vinculados ambos a una idea de democracia participativa más que a los principios de la democracia representativa.

La colisión entre los intereses de los administrados y del Estado puso en tela de juicio el prestigio del ombudsman al crear una situación çtemporaria? de descrédito de la institución, que en Derecho comparado goza de reputación y de auctoritasen tanto y en cuanto imprima a su accionar un carácter verdaderamente tuitivo. En el caso que hemos descrito, la paradoja es la siguiente: ¿cuáles intereses debe defender el defensor del pueblo de la nación argentina cuando su función es negada por quienes lo diseñaron constitucionalmente? La confianza de los usuarios es la condición esencial para ampliar el crédito de las instituciones políticas estatales y, tratándose de una institución que constituye un punto de equilibrio entre la administración y los derechos de los ciudadanos, el ombudsman necesita de la "creencia" de la opinión pública acerca de las virtudes de su accionar. Donald Rowat diagnosticó hace varios años que el ombudsman no podría hacer frente a un sistema político en el que la administración estuviese plagada de favoritismo y corrupción, y dominada por las presiones del Ejecutivo y de los partidos políticos. La consecuencia mediata de esta dependencia sería la pérdida de su credibilidad. ${ }^{38}$ Nada dijo, sin embargo, de los efectos que puede producir la negligencia del poder Ejecutivo ante las acciones y recomendaciones presentadas por el ombudsman en un campo tan conflictivo como el de las privatizaciones; ni sobre los vínculos que deben unir a las empresas monopólicas prestatarias de strvicios públicos y a la sociedad civil.

En virtud de la resolución negativa de este caso, la Declaración de Bucnos Aires, redactada por los miembros del Instituto Internacional del Ombudsman que se reunieron en el vi Congreso Internacional, organizado por el defensor del pueblo argentino, acondaron reafirmar las caracteristicas esenciales que debe tener todo ombudsman, es decir; independencia, accesibilidad, flexibilidad y credibilidad; además, establecieron como una de las prioridades de aquél controlar las actrvidades administrativas de gobiemos y servicios trúblicos. Dichos temas, que permiten discutir acerca de lo que es legal y de lo que es socialmente justo en las políticas de Estado, fueron reiterados por los defensores que asistieron al ur Congreso Anual de la Federación Iberoamericana de Ombudsman, realizado en Lima en 1998. El propio defensor español en su conferencia inaugural sentenció que el proceso de globalización y privatización de América Latina se apoya en el libre nercado e ignora, por ende;

\footnotetext{
17 Cunvo infoume anual, tomo 1, p. 13.

3P Donald Rowit, El owbudsman en el mundo, Barcelona, Teide, Presentación ele Frederic Rahola, sindic de Greuges de Barcelona, 1990, p. 147; la. exl., 1985, University Press of America, bajo el titulo The Onwhdswan Plan. The Woridruide Stread of an Idea.
} 
el "déficit social" que acarrea la economía de corte neoliberal. Quizá por ello la Declaración de Lina -redactada como corolario de los debates producidos en el seno de la reunión-destacó la existencia de la relación asimétrica, aunque legal, entre la ciudadanía y las empresas monopólicas. "Aum en el contexto del proceso de privatizaciones [concluyó la Declaración] se impone la necesidad de que los servicios públicos básicos sean accesibles a la población en general, especialmente a la de menores recursos." $" 39$

Desde 1996 se han reiterado situaciones similares que desvirtúan la relación del ombudsman con el poder Ejecutivo. Bajo el sugerente titular Absolutamente injusto, el defensor del pueblo argentino ha publicado su crítica a la disposición gubernamental de aumen to de otros servicios públicos, y ha señalado una y otra vez que el incremento "podrá ser legal, podrá ser contractual, pero es absolutamente ilegítimo, injusto e inequitativo". Para diferenciar nuevamente el ámbito legal del legítimo ha hecho uso, como vemos, de la categoría equidad, por la cual el auunento podía ser insignificante para algunos, pero para la mayoría de los ciucladanos "representa dinero que no tienen para cosas esenciales, como por ejemplo alimentar a su familia". "40 Los excesos y abusos del poder generan injusticia, insatisfacción y desprotección de los ciudadanos, los más olvidados en el proceso de liberalización económica que están llevando adelante los países latinoamericanos insertos en el proyecto global de privatización de las empresas estatales. Sabemos que, de acuerdo con la Constitución, el ombudsman debe asegurar el reconocimiento del poder de los administrados mediante el uso de reconendaciones y sugerencias de cambio de leyes injustas. La propia índole de la institución le impide modificar la normativa juridica cuestionada porque carece de fuerza vinculante, pero, ante su carencia de poder, el reproche conviene en ser de tipo moral y público. En el caso que venimos narrando, la impugnación de la medida estatal se basó en un argumento fundado en la idea de imjusticiay, por ello, cl ombudsman utilizó expresanente el concepto de justicia social para referirse a la gestión de la institución frente al desconocimiento que hace la administración de los derechos de las personas. Así, los conceptos justicia y derecho entraron en contradicción pero también definieron nuevas maneras de concebir la identidad ciudadana.

La Constitución argentina establece en suartículo 42 que los constumidores y usuarios de bienes y servicios tienen derecho a una información adecuada y veraz, a la libertad de elección y a condiciones de trato equitativo y digno. La Carta Magna, por ende, obliga a las autoridades a proporcionar la protecrión de esos derechos y a luchar contra la peruirbación de los mercados. El caso estudiado generó en torno a sí un cúmulo de expectativas por su posibilidad de sentar un precedente para la resolución de futuras situaciones análogas. Legalidad, legitimidad y justicia social fueron categorías que afloraron de manera paralela al debate sobre el verdadero rol que le

99 Referencias en Fermando Álvatez de Miranda, "Discurso inaugural", del III Congren Anual de ha Falención Deraumericana del Ombadsonan, Lima, Perí, sptiembere de 1998, co butpk//ombudsman.gob. pe, corno presidente de la FIO y defensor del pueblo de Espầ. Cuvinien, 20-09-1995.

${ }^{\text {to }}$ Crónien. 18-10-1998. 
tocaba desempeñar al ombudsman en tanto que ente recién integrado a la estructura estatal, y acerca de la redefinición del conceptc ciudadania. La concepción que el ombudsman tiene de la ciudadanía se vincula con la idea de que la persona no es sólo ciudadana a la hora de votar, sino también en el momento de exigir, reclamar y quejarse ante la administración y el poder. En la defensoría desaparecen los vocablos usuario y cliente, más propios de las empresas monopúlicas;

[...] empleamos, en cambio, los vocablos "ciudadano" -superando su relación con el ejercicio de los derechos políticos-.., "contribuyente" - más allá del estrecho marco del derecho tributario y de la práctica ciudadana que lo identifica con obligación impositiva-- o "interesado". Ante la institución del defensor del pueblo, la persona, el individuo, el hombre, la mujer, no son sólo ciudadanos para votar o contribuyentes para pagar sino que, precisamente porque son ciudadanos y pagan sıs impuestos, están en condiciones de exigir de las autoridades el respeto pleno de sus derechus. Y como defendemos derechos humanos, trascendemos edades, sexos, situación social o jurídica, condición económica o cualquier otro clemento que implique una minusvalía de aquellos derechos. ${ }^{41}$

Recapitulando las ideas expuestas a lo largo de este trabajo, es posible afirmar que $\mathrm{el}$ planteamiento del ombudsman es similar al que en el siglo xvil argumentó Montesquieu al referirse a la coexistencia de las leyes positizins, creadas por los seres humanos, con las relaciones de justicia posibles que condicionan el desconvolvimiento real de aquéllas y que parecerían surgir del universo del Derecho natural. Para Montesqtaeu, el ámbito de lo justo y de lo injusto tenía existencia "fuesa" de las leyes que ordenan y prohíben determinadas conductas; asinismo, estaba determinado por relaciones de equidad anteriores a la norma jurídica. ${ }^{42}$ Sobre la fundamentación de esta construcción se discute todavía hoy la noción de "justicia social" entendida como opuesta, en muchas oportunidades, a la propia ley. El caso analizado concuerda claramente con rsta oposición y, gracias a él, hemos podido comprobar que el debate sobrc la idea de justicia permanece abierto, no sólo porque se trata de un concepto de difícil categorización, pese a que forma parte del núcleo central de la ciencia del Derecho, sino por el variable campo semántico con el que está vinculado ${ }^{43}$ y por la oposición y división entre justicia legal y justicia sncial. Los argumentos del ombudsman, por otro lado, constituyen un desideratum que parecería emitir a la tradicional controversia entre Derecho natural y Derecho positivo sin lograr decidirse por ninguna de las dos construcciones, es decir, sin tomar partido por las posiciones iusnaturalistas, ni pensar en el Derecho positivo como el único conpus válido por su derivación estatal (positivismo jurídico). En todo caso, como ha señalado Norberto Bobbio, podríamos hablar de la pervivencia de una concepción del Derecho de tipo dualista y no monista, ${ }^{44}$

4l Segundo informe anual, tomo 1. PP. XXTX-XXX; La Rn:án, 22-12-1995, p. 28.

"2 Charles Louis de Secondat, barón de Muntesquieu, Del espiritu de las leyes, México, Editonial Porrita, 1998, 12a. ed., 1a. ed., Ginebra, 1748.

43 Roscoe Pound, Justicia confonme a Derecha, México, Editorial Letras, 1965, p. 1.

4 Norberto Bobbio, El paritinismo juridion. Lecciones de filosofin del Derecho, Madrid, Delaate, 1993, p. 45. 
to que evidentemente condiciona tanto ta imagen social d.1 ombudsman como la segutridac! que tebe prestuponer todo orden jurídico modemo. En este sentido, el ombudswon se convierie en el eje articulador entre la administración estatal y las personas, y su acturación se produce sobre la base de la construcción legal y jurídica que cunasa de la autoriclad legítima. Su reacción, sin embargo, se fiundamenta en el cuestionamicnto de la cruación del ámbito de la legalidad, en cuyos límites se sitúa la conceptualización de lo jesto/iajusto asentada en criterios de equidad que surgen cle la exterioridad no definida ui corporizada. El tema que abordamos pretende abrir nuevos horizontes seflexivos sobre la articulación de la sociedad civil y el Estado, pero tambión replanteas la analogía a la que estamos labituados, a saber considera al Derechoy al Estado como lo mismo.

Frente a las ilusiones ficticias que produce el estudio de la regularidad, consideramos que cada encuentro infer personal contiene una cscala microscópica en la que se: asnifiesta la interacción entre lo particular y lo normativo. Este diálogo conjuga con. textos sociales y elementos específicos que tienen lugar en situaciones concretas di: cambio. Por ello, henos elegido aproximamos a la comprensión del concepto justirya en cl proceso de renegociación de la realidad social más que en la definición absuracta de su concenido, y lo hemos hecho mediante una institución que: liene: (o debe tener) la peculiaridad de poder escapar a la función coactiva yue el diseño estatil le atribuye al espacio jurisdiccional y que hace de él un ámbito en el que sus titulares se ven constreñidos a aplicar las reglas y nomas establecidas por el Estado, que se presenta cono el único creador del Derecho. El reto está planteado, entonces, en torno a los riesgos que supone dejar fuera de: la legalidad las formas y posibilidades reales de resolución de los conflictes que se plantean eu las fironteras iuternas del aprrato estatitl.

IV . FUENTES CONSULTADAS

Canadă (IOI): International Ombudsman Institute, hup://www.laıv.ualberta.ca/ sentres/ioi.

Buenos Aires: Defensor del pueblo de la nación argentina, htp: / wwwdefensorgoviar:

Costa Rica: Defensoria de los habitantes de lit República de Costa Rica: http:// mwvernet.cr/defensor.

México: Comisión Nacional de Derechos Humanos, htpt//www.cndh.org.mx.

Perú: Defensor del pueblo, http://wwwombudsman.gob.pe. 
Informes anuales del defensor del pueblo de la nación argentina:

Primero (1994) del 17-10-1994 al 31-12-1994, 3 vols.;

Segundo (1995) del 01-01-1995 al \$1-12-1995, 3 vold.;

Tercero (1996) del 01-01-1996 al 31-12-1996, 2vols.;

Cuarto (1997) del 01-01-1997 al 31-12-1997, 2 vols.;

Quinto (1998) del 01-01-1998 al 31-12-1998, página web http: / /defensor.govar: 